\title{
Retraction Note to: Foraging of Host-Habitat and Superparasitism in Cotesia glomerata: A Gregarious Parasitoid of Pieris brassicae
}

\author{
Fazil Hasan • M. Shafiq Ansari • Nadeem Ahmad
}

Published online: 7 February 2013

(C) Springer Science+Business Media New York 2013

Erratum to: J Insect Behav (2011) 24:363-379

DOI 10.1007/s10905-011-9262-z

The Journal of Insect Behavior was notified in December 2012 of the possibility of plagiarism in "Foraging of host-habitat and superparasitism in Cotesia glomerata: A gregarious parasitoid of Pieris brassicae"; Fazil Hasan, M. Shafiq Ansari and Nadeem Ahmad, Journal of Insect Behavior, Vol. 24: 363-379. After careful review, the Co-Editors determined that article did include significant plagiarism of "Superparasitism in Cotesia glomerata: response of hosts and consequences for parasitoids," Hainan Gu, Qun Wang and Silvia Dorn, Ecol. Entomol. 2003,Vol. 28: 422-431. Consequentially, the Journal of Insect Behavior retracts the article and will not consider for publication future submissions by the offending authors.

The online version of the original article can be found at http://dx.doi.org/10.1007/s10905-011-9262-z.

$\overline{\text { F. Hasan }(\bowtie) \cdot M . ~ S . ~ A n s a r i ~} \cdot$ N. Ahmad

Department of Plant Protection, Faculty of Agricultural Sciences, Aligarh Muslim University,

Aligarh 202002, India

e-mail: fazilento10@gmail.com 